\title{
Secondary organic aerosol reduced by mixture of atmospheric vapours
}

\section{McFiggans, Gordon}

\section{9-01-31}

McFiggans , G , Mentel , T F , Wildt , J , Pullinen , I , Kang , S , Kleist , E , Schmitt , S , Springer , M , Tillmann, R, Wu , C, Zhao, D , Hallquist , M , Faxon , C , Le Breton , M , Hallquist , A M , Simpson, D , Bergstroem , R , Jenkin , M E , Ehn , M , Thornton , J A , Alfarra , M R , Bannan , T J , Percival , C J , Priestley , M , Topping , D \& Kiendler-Scharr , A 2019 , ' Secondary organic aerosol reduced by mixture of atmospheric vapours ', Nature , vol. 565 , no. 7741 , pp. 587-593 . https://doi.org/10.1038/s41586-018-0871-y

http://hdl.handle.net/10138/306256

https://doi.org/10.1038/s41586-018-0871-y

submittedVersion

Downloaded from Helda, University of Helsinki institutional repository.

This is an electronic reprint of the original article.

This reprint may differ from the original in pagination and typographic detail.

Please cite the original version. 


\section{Secondary organic aerosol reduced by mixture of atmospheric vapours}

Gordon McFiggans ${ }^{1}$, Thomas F. Mentel $^{2}$, Jürgen Wildt ${ }^{2,3}$, Iida Pullinen ${ }^{2,15}$, Sungah Kang $^{2}$, Einhard Kleist ${ }^{3}$, Sebastian Schmitt ${ }^{2,16}$, Monika Springer ${ }^{2}$, Ralf Tillmann ${ }^{2}$, Cheng $\mathrm{Wu}^{2,17}$, Defeng Zhao ${ }^{5,2}$, Mattias Hallquist ${ }^{6}$, Cameron Faxon ${ }^{6}$, Michael Le Breton $^{1,6}$, Åsa M. Hallquist ${ }^{7}$, David Simpson ${ }^{8,12}$, Robert Bergström ${ }^{6,8,13}$, Michael E. Jenkin ${ }^{9}$, Mikael Ehn ${ }^{10}$, Joel A. Thornton ${ }^{11}$, M. Rami Alfarra ${ }^{1,14}$, Thomas J. Bannan ${ }^{1}$, Carl J. Percival ${ }^{1,18}$, Michael Priestley ${ }^{1}$, David Topping ${ }^{1,14}$, Astrid Kiendler-Scharr ${ }^{2,4}$

\section{University of Manchester, School of Earth and Environmental Sciences, Oxford} Road, Manchester, M13 9PL, UK

2. Institut für Energie- und Klimaforschung, IEK-8, Forschungszentrum Jülich, 52425 Jülich, Germany

3. Institut for Bio- and Geosciences, IBG-2, Forschungszentrum Jülich, Jülich 52425, Germany

4. I. Physikalisches Institut, Universität zu Köln, 50937 Köln, Germany

5. Department of Atmospheric and Oceanic Sciences \& Institute of Atmospheric Sciences, Fudan University, Shanghai, China

6. Atmospheric Science, Department of Chemistry and Molecular Biology, University of Gothenburg, SE-41296 Gothenburg, Sweden

7. IVL Swedish Environmental Research Institute, PO Box 5302, SE-400 14 Gothenburg, Sweden

8. Department of Earth, Space and Environment, Chalmers University of Technology, 41296 Gothenburg, Sweden

9. Atmospheric Chemistry Services, Okehampton, Devon, EX20 4QB, UK

10. Institute for Atmospheric and Earth System Research / Physics, Faculty of Science, University of Helsinki, P.O. Box 64, 00014, Helsinki, Finland

11. Department of Atmospheric Sciences, University of Washington, Seattle, WA98195, USA

$$
\text { 12. EMEP MSC-W, Norwegian Meteorological Institute, Oslo, Norway }
$$

13. Swedish Meteorological and Hydrological Institute, 60176 Norrköping, Sweden

14. National Centre for Atmospheric Science (NCAS), Oxford Road, Manchester, M13 9PL, UK

15. Department of Applied Physics, University of Eastern Finland, 70211 Kuopio, Finland

16. TSI GmbH, 52068 Aachen, Germany

17. Stockholm University, Department of Environmental Science \& Analytic Chemistry, SE-10691 Stockholm, Sweden

18. Jet Propulsion Laboratory, California Institute of Technology, Pasadena, CA 91109, USA 
Secondary organic aerosol contributes to the atmospheric particle burden with implications for air quality and climate. Biogenic volatile organic compounds emitted from plants are important secondary organic aerosol precursors with isoprene emissions dominating globally. However, its yield of particle mass from oxidation is generally modest compared to that of other terpenoids. Here we show that isoprene, carbon monoxide and methane can suppress the instantaneous mass and the overall mass yield derived from monoterpenes in mixtures. We find that isoprene scavenges hydroxyl radicals preventing reaction with monoterpenes and the resulting isoprene peroxy radicals scavenge highly oxygenated monoterpene products. These effects reduced the yield of low-volatility products that would otherwise form secondary organic aerosol. Global model calculations indicate that oxidant and product scavenging can operate effectively in the real atmosphere. Highly reactive, modest aerosol yield compounds are not necessarily net producers and their oxidation can suppress both particle number and mass.

\section{Introduction}

The secondary organic fraction of fine aerosol is substantial ${ }^{1,2}$ and contributes significantly to the fine particulate matter (PM) burden ${ }^{3}$ and aerosol impacts on climate $^{4}$. Conventionally, Secondary Organic Aerosol (SOA) particle mass is considered to be formed independently from the condensable oxidation products of each contributing volatile organic compound (VOC) $)^{5}$. The ambient atmosphere is a complex mixture of biogenic and anthropogenic VOC, a limited number of which are normally considered to control the oxidant concentrations in air quality or climate models $^{4,5}$. Isoprene has been found to dominate plant VOC emissions globally ${ }^{6,7}$, though it has been found only moderately effective at forming SOA particle mass ${ }^{8,9,10}$. Nevertheless, isoprene oxidation tracers have been observed in particles in both chamber experiments ${ }^{11,12}$ and the atmosphere ${ }^{11,13,14,15}$ showing that they condense from the gas phase. Oxidation of the monoterpenes (MT), including $\alpha$-pinene, and sesquiterpenes is generally more efficient at producing SOA particle mass ${ }^{16,17,18}$. When oxidation of a VOC contributing to SOA is explicitly considered in models, some interaction between the oxidant field and the SOA formation process is implicit ${ }^{5}$, though recently observed behaviour is yet to be described. Two such recent findings have motivated the current work. First, it has been shown that $\mathrm{C}_{5}$ isoprene molecules suppress the nucleation of SOA particles in the oxidation of the $\mathrm{C}_{10}$ MT in mixtures of plant emissions by successfully competing for the hydroxyl radical, $\mathrm{OH}^{19,20,21}$. Second, recent direct observation of highly oxygenated organic molecules (HOM) formed from MT oxidation ${ }^{22}$, and elucidation of the auto-oxidation mechanisms by which they are formed, have implicated them in the formation of new SOA particles. Our work moves beyond the suppression of particle nucleation by isoprene using the new mechanistic understanding to explain SOA mass and yield suppression in MT-containing mixtures. These results highlight a need for more realistic consideration of SOA formation in the atmosphere analogous to the treatment of ozone formation, where interactions between the mechanistic pathways involving peroxy radicals are recognised to be essential ${ }^{23}$. 
Ostensibly, the concept of a SOA yield is straightforward and unambiguous ${ }^{24-26}$. It has been widely used to interpret the potential of precursor molecules to produce particulate mass, most extensively from smog chamber studies and usually with the goal of quantifying the formation of ambient atmospheric particles. Yield is normally defined in terms of the particulate mass condensed for a given mass of gaseous parent VOC consumed. The process of determining SOA yields presents substantial practical challenges. Notwithstanding measurement uncertainties and artefacts (for example, wall losses and those associated with the accurate determination of the mass of semivolatile materia ${ }^{27-31}$ ) there are numerous reasons why SOA yields may vary according to the conditions under which they are measured. This paper does not aim to provide a critical evaluation of the determination of SOA yields and their extrapolation to atmospheric conditions and the reader is referred to a number of recent publications for a discussion of challenges and the state-of-the-science concerning the interpretation of SOA formation from chamber experiments ${ }^{22,27,29-32}$. However, there are conceptual aspects often implicit in the treatment of SOA formation either in chamber experiments, real atmospheric mixtures, or models of the atmosphere that provide the context for the current study.

First, the concept of yield frequently includes some assumption of equilibrium. An interpretation of particle mass in terms of the partitioning of components of known volatility by absorptive partitioning invokes an equilibrium assumption. In reality, mass takes a finite time to transfer between the continuous and dispersed phases ${ }^{33,34}$. Second, a parent VOC will continue to react, as will its reaction products, provided they have reaction partners. Under atmospheric, or simulated atmospheric, conditions the reaction partners are normally oxidants, such as the hydroxyl radical $\mathrm{OH}$ (the main focus in this paper). This means that the distribution of vapour phase components that is available to transfer to the condensed phase by condensational growth or nucleation is continuously evolving through photochemical reactions. Third, a yield integrates across all oxidation products formed from the parent hydrocarbon, summing the fraction of these products that will partition to the particle phase from whatever stage of oxidation under the chosen reaction conditions. We further would like to note that the yields themselves can be dependent on the oxidant concentration ${ }^{\text {e.g.31,32.32 }}$.

This combination of characteristics raises first order challenges when considering SOA formation in the real atmosphere which comprises a complex mixture of organic vapours of widely varying volatilities, from numerous sources of anthropogenic and biogenic origin. This paper is concerned with the challenge surrounding the introduction of oxidants into the atmospheric mixture and the reactivity of the evolving components in the mixture - specifically, the yield of condensed organic particulate material of any of the single component vapours in the mixture when it is consumed by the oxidant. Any of the vapours may react with the available oxidant, so from the perspective of any other vapour molecule, the oxidant has been "scavenged" and is unavailable as a reaction partner. Our experimental systems illustrate the implications on SOA formation of mixtures of precursors. We demonstrate how SOA yield in mixtures is dependent on whether the reactivity of one of the SOA forming compounds controls the oxidant and contrast conditions in the laboratory and the atmosphere. It is not only the oxidants that can be removed from the system by components of a mixture. The products from oxidation that can react to form the final condensable SOA precursors may alternatively be scavenged by other reactive intermediates. This process can form the basis for the reduction in yield of the individual components in a mixture, as shown by our results below and detailed in the supplement sections. 


\section{Experiments to SOA formation in mixtures}

140 In the Jülich Plant Atmosphere Chamber (JPAC; suppl. section 1) we find that the presence of isoprene substantially suppresses the SOA mass formed from oxidation of $\alpha$-pinene, the most abundant MT in the atmosphere (Figure 1A). Furthermore, we show that this reduction of SOA mass is not trivially due to the lower amount of MT consumed in the presence of isoprene. Rather the presence of isoprene actually suppresses the SOA mass yield from the amount of VOC consumed (Figure 1B). Isoprene thereby limits not only new particle formation ${ }^{19}$ (hence exhibiting control over particle number concentration) but also the growth of pre-existing particles and thus their size. This has significant consequences for the abundance of PM mass formed in the mixture and the number of particles that may grow to sizes where they can act as cloud seeds. Our findings are surprising and unexpected in the context of existing conceptions of SOA mass yields (suppl. section 2). As shown in Figure 1, the presence of isoprene substantially suppresses the SOA mass formation from $\alpha$-pinene oxidation by about $60 \%$ and the SOA yield by $40 \%$. Figure S2 shows even greater suppression in greater isoprene excess, with both mass and yield reduced in the presence of both neutral and acidic seed. This contrasts sharply with current understanding, since isoprene oxidation should contribute substantially to SOA production when isoprene concentrations are high.

Below we describe the two effects contributing to SOA suppression - oxidant scavenging and product scavenging. This demonstrates the importance of accounting for the reactivity of the parent VOC in atmospheric mixtures and hence their turnover (suppl. section 2) as well as interactions between their reaction intermediates and products. Whilst our experiments illustrate this requirement predominantly with reference to the photochemical isoprene - $\alpha$-pinene system with $\mathrm{OH}$ as the major oxidant, it should be noted that in all mixed systems investigated, $\mathrm{OH}$ (oxidant) scavenging and product scavenging were found to reduce both the SOA particle mass and the SOA yield. Note that during daytime, both, ozonolysis and $\mathrm{OH}$ oxidation of $\alpha$ pinene, contribute to SOA, as in our experiments, however the contribution via $\mathrm{OH}$ reactions here was much greater than $90 \%$. According to our mechanistic understanding presented below, product scavenging will be similarly effective for $\mathrm{OH}$ and $\mathrm{O}_{3}$ oxidation.

\section{Oxidant and product scavenging}

Oxidant scavenging is demonstrated by the decrease in SOA mass and yield of the mixture with increasing isoprene fraction as well as by the decrease of the $\alpha$-pinene yield itself (Figure 1B and suppl. section 3). The contribution of isoprene to SOA mass in the presence of neutral ammonium sulfate aerosols is small and $\alpha$-pinene oxidation products make up the overwhelming fraction of SOA in mixtures. Isoprene increasingly efficiently competes with $\alpha$-pinene for the available $\mathrm{OH}$ as the reaction system is stepped from high SOA yield pure $\alpha$-pinene to low SOA yield pure isoprene (Figure $\mathrm{S} 2$ ). With respect to $\alpha$-pinene, the isoprene "scavenges" the $\mathrm{OH}^{19}$, i.e. the steady state $\mathrm{OH}$ concentration is lowered by the introduction of isoprene for a given $\mathrm{OH}$ source strength, therefore less $\mathrm{OH}$ can react with $\alpha$-pinene, resulting in less SOA mass being formed. In addition, the SOA yield itself is dependent on $[\mathrm{OH}]^{31,32}$.

By uniquely being able to control the $\mathrm{OH}$ at the same concentration with and without isoprene addition by readjusting its source strength, we were able to reveal that the SOA 
mass (Figure 1A), and by implication the $\alpha$-pinene SOA yield (Figure 1B, $3^{\text {rd }}$ bar), decreased with increasing isoprene in the mixture (suppl. section 4). Strikingly, the $\alpha$ pinene SOA yield was reduced by $30 \%$ relative to the pure $\alpha$-pinene yield, even though the $\mathrm{OH}$ scavenging effect has been removed ( $\Delta$ isoprene $/ \Delta \alpha$-pinene $\approx 1 \pm 0.2[\mathrm{ppb} / \mathrm{ppb}]=$ $0.5 \pm 0.1[\mu \mathrm{g} / \mu \mathrm{g}])$. Moreover, by re-adjusting [OH], we held the $\alpha$-pinene sub-system of the mixture at the same stage of oxidation as in the pure case. This results in the condensing oxidation products having the same "chemical age" in both cases, thereby avoiding comparison of chemical systems of different chemical evolution.

In Figure 2 we show the actual $\alpha$-pinene SOA yields (yact) in the mixture normalized to the $\alpha$-pinene SOA yield $\mathrm{y}_{\mathrm{AP}}=17 \%$ for pure $\alpha$-pinene in absence of isoprene. The yact were calculated from the observed SOA mass and the actual consumption of $\alpha$-pinene. Depending on the isoprene to $\alpha$-pinene ratio, SOA mass produced from the same amount of consumed $\alpha$-pinene in the presence of isoprene can be reduced by more than half compared to the amount formed when oxidised alone (Figure 2). Clearly, smaller amounts of SOA forming products from $\alpha$-pinene oxidation are formed in the presence of isoprene - we denote this effect "product scavenging" .

The product scavenging effect (and the $\mathrm{OH}$ scavenging effect) on SOA formation is somewhat masked in the presence of the acidic seed aerosol with which isoprene has a significant yield ${ }^{12,35-37}$ (suppl. section 4, Figure S3, Figure 1B, $6^{\text {th }}$ bar). Replacing isoprene by $\mathrm{CO}$ shows, that the acidity of the seed particles did not affect the behaviour of $\alpha$-pinene (Figure S3), but indeed enhanced the isoprene contribution (Figure S4). This underlines the importance of liquid phase processes for isoprene, but also clearly shows that both scavenging effects are general phenomena in the gas phase.

SOA yield suppression also occurs when isoprene is mixed with $\beta$-pinene and when $\mathrm{CO}$ or $\mathrm{CH}_{4}$ were mixed with $\alpha$-pinene (suppl. section 5, Figures S5-S7, Figure 4). This generality ensures that the influence of the relative reactivity of components in mixtures on the SOA formation potential has much more profound implications than a simple reduction in yield in each of the binary mixtures. Moreover, because of potential interactions with additional SOA contributors, the yields in anything beyond the binary mixtures cannot be simply added or in any way predicted without specific mechanistic insight.

The key to a mechanistic understanding of the product scavenging is the formation of HOM with the peculiarity that HOM peroxy radicals also dimerise in the gas phase ${ }^{38}$ (suppl. section 6). It can be inferred from their structure and $\mathrm{O} / \mathrm{C}$ ratios that $\mathrm{HOM}$ and even moreso their dimers, are low to extremely low volatility organic compounds ${ }^{22,39}$ and will contribute substantially to SOA formation and initial growth ${ }^{22,39}$.

In Figure 3A we present direct observation of the product scavenging of $\alpha$-pinene HOM by comparing mass spectra measured in $\mathrm{OH}$ reaction systems for $\alpha$-pinene-only and for an $\alpha$-pinene/isoprene mixture. For $\alpha$-pinene-only we observed about equal signal intensities in the ranges of $\alpha$-pinene HOM monomers with $10 \mathrm{C}$-atoms and of HOM dimers with 17-20 C-atoms. In the presence of isoprene, $\alpha$-pinene dimers are suppressed by a factor of about 3. Comparable dimer suppression by a factor of 2 is observed for CO (Figure 4A). HOM dimers have been observed in the boreal ambient atmosphere, lower during daytime than at night-time, but at lower fractions than in our $\alpha$-pinene-only experiments ${ }^{40,41}$. Since product scavenging will be occurring, particularly during daytime, these observations are consistent with our findings.

The strength of product scavenging is estimated by comparing two sets of experiments where the $[\mathrm{OH}]$ was tuned, either by varying the $\mathrm{OH}$ sink through adding different amounts of isoprene to the reaction system or by varying the $\mathrm{OH}$ production rate through modifying the photolysis rate $\mathrm{J}\left(\mathrm{O}^{1} \mathrm{D}\right)$ for $\mathrm{O}_{3}$ (Figure $3 \mathrm{~B}$ ). With increasing 
isoprene, the dimers are more strongly suppressed than with decreasing $\mathrm{J}\left(\mathrm{O}^{1} \mathrm{D}\right)$ as a result of increased scavenging of $\alpha$-pinene HOM peroxy radicals by isoprene related $\mathrm{RO}_{2}$ and $\mathrm{HO}_{2}$ radicals ${ }^{42}$. This leads to formation of less HOM, mainly by diminishing $\alpha$-pinene HOM self-dimerization. Suppression of the HOM dimers alone accounts for $27 \%$ reduction in HOM mass (Figure 3C) and explains most of the 35\% SOA mass reduction by the product scavenging effect shown in Figure 1, underlining the pivotal role of HOM dimers in new particle and SOA formation ${ }^{22,39}$. The involvement of HOM does not preclude the involvement of multigenerational oxidation as such (cf. suppl. section 6). Indeed, the non-linear dependence of the total HOM on the turnover in Figure 3B requires at least a second oxidation step and explains the dependence of the $\alpha$-pinene SOA yield on $[\mathrm{OH}]$, contributing to the $\mathrm{OH}$ scavenging effect.

The mechanism of product scavenging via dimer suppression by short chained peroxy radicals or $\mathrm{HO}_{2}$ is general for peroxy radical chemistry and is not limited to the presence of isoprene in the mixture. It is effective in mixtures of $\alpha$-pinene with $\mathrm{CO}$ via $\mathrm{HO}_{2}$ (Figure 4) and with $\mathrm{CH}_{4}$ via $\mathrm{CH}_{3} \mathrm{O}_{2}$ radicals (Figures S7). $\mathrm{CO}$ and $\mathrm{CH}_{4}$ are extreme cases, each with essentially no SOA yield. In both cases, the scavenging effects are solely related to gas-phase chemistry and independent of aerosol composition: organic or inorganic neutral or inorganic acidic particles. We therefore conclude that product scavenging effect is a general effect in mixtures of VOC.

\section{Atmospheric implications}

Our new findings in JPAC would hold in atmospheric concentration regimes (suppl. section 7). However, in the atmosphere, the $\mathrm{OH}$ concentration is not solely controlled by the isoprene / $\alpha$-pinene ratio as in the JPAC chamber. Simulations using the EMEP MSC-W model ${ }^{43,44}$ (suppl. section 8) show that the scavenging effects by isoprene under realistic atmospheric conditions lowers the $\mathrm{OH}$ concentration compared to the hypothetical "no isoprene" case and affects the SOA formation. However, even at small isoprene SOA yields, the gains of isoprene SOA and $\mathrm{MT}-\mathrm{O}_{3}-\mathrm{SOA}$ offset the reduction from $\mathrm{OH}$ scavenging (Figure 5, noIso, OHS). When a parameterisation of the product scavenging constrained to our measurements (Figure 2) is included in the global model simulations, we find that photochemically generated MT-OH-SOA is strongly suppressed, in areas with sufficiently high MT and isoprene emissions (Figure 5, PS). The dramatic effects on MT-OH-SOA show the potential for product scavenging to reduce aerosol loadings substantially in many regions of the world, even more so if one considers that product scavenging similarly could also affect e.g. the MT-O $3-S O A$ (Figure 5, PSox). It is not possible to be so sure about the magnitude of $\mathrm{OH}$ scavenging from all potential reactants, since more measurement constraint is needed to include mechanistic descriptions in such systems.

Extending our results from mixtures of isoprene, $\mathrm{CH}_{4}$, and $\mathrm{CO}$ with $\alpha$-pinene or $\beta$ pinene to the reactive atmospheric mixture of vapours, any of the reaction products from any of the components in the mixture may react together, such that from the perspective of any of the others, they have been "scavenged" from the mixture. Similarly, from the perspective of the formation of organic particulate material, some of the condensable oxidation products that are direct precursors may be "scavenged", in all cases reducing the ambient yield. Spatial distribution of short chain organic compounds and specific composition of the reaction mixture will determine the strength of the $\mathrm{OH}$ and the product scavenging effects. Whilst long lived compounds, like $\mathrm{CH}_{4}$, may act ubiquitously in cleaner regions of the earth, compounds with strong anthropogenic sources, like CO, may not exert their full scavenging potential because, when high in concentration, they are always accompanied by high concentrations of 
other pollutants, like $\mathrm{NO}_{\mathrm{x}}$. While oxidant scavenging will take place under nearly all conditions, product scavenging across SOA precursors is a complex function $\mathrm{RO}_{2}$ terminating agents, such as peroxy radicals of VOC with moderate or no SOA yield, $\mathrm{HO}_{2}$, and $\mathrm{NO}_{\mathrm{X}}$. Product scavenging and "non-additivity" of SOA yields will thus vary from region to region, accordingly. Without further experimentally constrained parameterisation of the interactions between all relevant components in realistic atmosphere, it is not possible to predict the magnitude and geographical distribution of suppression of SOA formation. Inclusion of explicit interactions of such complexity in global simulations is practically impossible. It is only possible to say for the considered systems that the SOA yields and net SOA mass must be reduced compared to linear addition of yields, even if the control of oxidant were realistically included.

\section{Outlook and recommendations}

Our findings demonstrate that SOA precursors with modest yields suppress SOA forming products of higher SOA yield precursors substantially. Our work directly challenges two widespread treatments of SOA formation and suggests an alternative mechanistically-based solution. A first obvious recommendation following this work is that the decoupling of the modulation of oxidant fields from SOA precursor turnover is clearly discouraged. We have further demonstrated that simple linear addition of SOA mass from the individual yields of components in a VOC mixture will likely lead to a substantial overestimation of SOA production. Measuring SOA yields with individual compounds leads to insight into the mechanisms of SOA production but the results do not reflect the conditions of the real environment. Such data should therefore be used with caution when modelling aerosol formation. In the general case, the abundance of $\mathrm{HOM}, \mathrm{HOM}-\mathrm{RO}_{2}$ and $\mathrm{RO}_{2}$ products from potential SOA precursors as well as from volatile compounds not producing SOA mass should be considered when predicting the mixture's yield. Our results highlight a need for more realistic consideration of SOA formation in the atmosphere analogous to the treatment of ozone formation, where interactions between the mechanistic pathways involving peroxy radicals are recognised to be essential ${ }^{23}$. It may be possible to produce lumped classes of precursors according to their likelihood of increasing or decreasing a mixture's yield and this could be a focus of further investigation.

It is likely that both background oxidant concentrations and VOC emissions (and hence $\mathrm{OH}$ reactivity) will change in the future. Without a reasonable representation of SOA yields in different atmospheric VOC mixtures it will not be possible to achieve predictive capability for the SOA contribution to particulate matter. 


\section{References}

1. Hallquist, M. et al. The formation, properties and impact of secondary organic aerosol: current and emerging issues. Atmos. Chem. Phys. 9, 5155-5236 (2009).

2. Jimenez, J. L. et al. Evolution of Organic Aerosols in the Atmosphere. Science, 326, 1525-1529 (2009)

3. Goldstein, A. H. \& I. E. Galbally, Known and Unexplored Organic Constituents in the Earth's Atmosphere, Environ. Sci. \& Technol. 41, 1514-1521 (2007).

4. Spracklen, D.V. et al. Aerosol mass spectrometer constraint on the global secondary organic aerosol budget. Atmos. Chem. Phys. 11, 12109-12136 (2011).

5. Kanakidou, M. et al. Organic aerosol and global climate modelling: a review. Atmos. Chem. Phys. 5, 1053-1123 (2005).

6. Guenther, A. et al. Estimates of global terrestrial isoprene emissions using MEGAN (Model of Emissions of Gases and Aerosols from Nature). Atmos. Chem. Phys. 6, 31813210 (2006).

7. Guenther, A. et al. The Model of Emissions of Gases and Aerosols from Nature version 2.1 (MEGAN2.1): an extended and updated framework for modeling biogenic emissions. Geosci. Model Dev. 5, 1471-1492, (2012).

8. Carlton, A.G., Wiedinmyer, C., \& Kroll, J.H. A review of Secondary Organic Aerosol (SOA) formation from isoprene. Atmos. Chem. Phys. 9, 4987-5005 (2009).

9. Clark, C.H. et al. Temperature Effects on Secondary Organic Aerosol (SOA) from the Dark Ozonolysis and Photo - Oxidation of Isoprene. Environ. Sci. \& Techn. 50, 5564-5571 (2016).

10. Liu, J. et al. Efficient Isoprene Secondary Organic Aerosol Formation from a Non IEPOX Pathway. Environ. Sci. \& Technol. 50, 9872-9880, (2016).

11. Edney, E.O. et al. Formation of 2-methyl tetrols and 2-methylglyceric acid in secondary organic aerosol from laboratory irradiated isoprene/NOX/SO2/air mixtures and their detection in ambient PM2.5 samples collected in the eastern United States. Atmos. Environ. 39, 5281-5289 (2005).

12. Surratt, J.D. et al. Reactive intermediates revealed in secondary organic aerosol formation from isoprene. Proc. Natl. Acad. Sci. USA 107, 6640-6645 (2010).

13. Claeys, M. et al. Formation of secondary organic aerosols from isoprene and its gas-phase oxidation products through reaction with hydrogen peroxide. Atmos. Environ. 38, 4093-4098 (2004). 
14. Robinson, N.H. et al. Evidence for a significant proportion of Secondary Organic Aerosol from isoprene above a maritime tropical forest. Atmos. Chem. Phys. 11, 10391050 (2011).

15. Xu L. et al. Effects of anthropogenic emissions on aerosol formation from isoprene and monoterpenes in the southeastern United States. Proc. Natl. Acad. Sci. USA 112, 37-42 (2015).

16. Lee, A. et al. Gas-phase products and secondary aerosol yields from the ozonolysis of ten different terpenes, J. Geophys. Res. 111, D07302 (2006).

17. Lee, A., et al. Gas-phase products and secondary aerosol yields from the photooxidation of 16 different terpenes, J. Geophys. Res. 111, D17305 (2006).

18. Ng, N. L. et al. Effect of NOx level on secondary organic aerosol (SOA) formation from the photooxidation of terpenes. Atmos. Chem. Phys. 7, 5159-5174 (2007).

19. Kiendler-Scharr, A. et al. New particle formation in forests inhibited by isoprene emissions. Nature 461, 381-384 (2009).

20. Kanawade, V.P. et al. Isoprene suppression of new particle formation in a mixed deciduous forest. Atmos. Chem. Phys. 11, 6013-6027 (2011).

21. Lee, $\mathrm{SH}$ et al. Isoprene suppression of new particle formation: Potential mechanisms and implications. J. Geophys. Res. Atmos. 121, 14,621-14,635 (2016).

22. Ehn, M. et al. A large source of low-volatility secondary organic aerosol. Nature 506, 476-479 (2014).

23. Jenkin, M.E., Derwent, R.G. \& Wallington, T.J. Photochemical ozone creation potentials for volatile organic compounds: Rationalization and estimation. Atmos. Environ. 163, 128-137 (2017).

24. Odum, J. R. et al. Gas/particle partitioning and secondary organic aerosol yields. Environ. Sci. \& Tech. 30, 2580-2585 (1996).

25. Hoffmann, T. et al. Formation of organic aerosols from the oxidation of biogenic hydrocarbons. J. Atmos. Chem. 26, 189-222 (1997).

26. Seinfeld, J. H. \& Pankow, J. F. Organic atmospheric particulate material. Ann. Rev. Phys. Chem. 54, 121-140 (2003).

27. Matsunaga, A. \& Ziemann, P. J. Gas-Wall Partitioning of Organic Compounds in a Teflon Film Chamber and Potential Effects on Reaction Product and Aerosol Yield Measurements. Aerosol Sci. Tech. 44, 881-892 (2010).

28. Zhang, X. et al. Influence of vapor wall loss in laboratory chambers on yields of secondary organic aerosol. Proc. Natl. Acad. Sci. USA 111, 5802-5807 (2014). 
29. Zhang, X. et al. Vapor wall deposition in Teflon chambers. Atmos. Chem. Phys. 15, 4197- 4214 (2015).

30. Krechmer, J. E., Pagonis, D., Ziemann, P. J. \& Jimenez, J. L. Quantification of GasWall Partitioning in Teflon Environmental Chambers Using Rapid Bursts of LowVolatility Oxidized Species Generated in Situ. Environ. Sci. Tech. 50, 5757- 5765 (2016).

31. Sarrafzadeh, M. et al. Impact of $\mathrm{NOx}$ and $\mathrm{OH}$ on secondary organic aerosol formation from $\beta$-pinene photooxidation. Atmos. Chem. Phys. 16, 11237-11248 (2016).

32. Eddingsaas, N. C. et al. Alpha-pinene photooxidation under controlled chemical conditions - Part 2: SOA yield and composition in low- and high-NOx environments. Atmos. Chem. Phys. 12, 7413-7427, (2012).

33. Zhang, X., Pandis, S. N. \& Seinfeld, J. H. Diffusion-Limited Versus QuasiEquilibrium Aerosol Growth. Aerosol Sci. Tech. 46, 874-885 (2012).

34. O'Meara, S., Topping, D. O. \& McFiggans, G. The rate of equilibration of viscous aerosol particles. Atmos. Chem. Phys. 16, 5299-5313 (2016).

35. Surratt, J. D. et al. Effect of acidity on secondary organic aerosol formation from isoprene. Environ. Sci. \& Techn. 41, 5363-5369 (2007).

36. Gaston, C. J. et al. Reactive Uptake of an Isoprene-Derived Epoxydiol to Submicron Aerosol Particles. Environ. Sci. \& Techn. 48, 11178-11186 (2014).

37. Riva, M. et al. Effect of Organic Coatings, Humidity and Aerosol Acidity on Multiphase Chemistry of Isoprene Epoxydiols. Environ. Sci. \& Techn. 50, 5580-5588 (2016).

38. Berndt, T. et al. Accretion Product Formation from Self- and Cross-Reactions of $\mathrm{RO}_{2}$ Radicals in the Atmosphere. Angew. Chem. Int. Edit. 57, 3820-3824 (2018).

39. Tröstl, J. et al. The role of low-volatility organic compounds in initial particle growth in the atmosphere. Nature 533, 527-531 (2016).

40. Mohr, C. et al. Ambient observations of dimers from terpene oxidation in the gas phase: Implications for new particle formation and growth. Geophys. Res. Lett. 44, 2958-2966 (2017).

41. Yan, C. et al. Source characterization of highly oxidized multifunctional compounds in a boreal forest environment using positive matrix factorization. Atmos. Chem. Phys. 16, 12715-12731 (2016).

42. Wennberg, P. O. et al. Gas-Phase Reactions of Isoprene and Its Major Oxidation Products. Chem. Reviews 118, 3337-3390 (2018).

43. Simpson, D. et al. The EMEP MSC-W chemical transport model - technical description. Atmos. Chem. Phys. 12, 7825-7865 (2012). 
44. Stadtler, S. et al., Ozone impacts of gas-aerosol uptake in global chemistry-transport models. Atmos. Chem. Phys. 18, 3147-3171 (2018)

\section{Author contributions:}

G.M, T.F.M., J.W. edited the manuscript and the supplement

G.M., T.F.M., J.W., A.K.S., M.H, D.S. M.E.J. conceptualized and planned the study, and conducted data interpretation

J.W. I.P., S.K., E.K., S.S., M.S., R.T., C.W., D.Z., C.F., M.L.B., Å.M.H., M.R.A., T.J.B., C.J.P., M.P., D.T conducted data collection and analysis

480 D.S., R.B., M.E.J. contributed the global model calculations

481 J.T., M.E., Å.M.H., M.H. provided specific inputs to manuscript and supplement All co-authors discussed the results and commented the manuscript and the supplement.

\section{Acknowledgements}

The EMEP modelling work has been partially funded by EMEP under UNECE. Computer time for EMEP model runs was supported by the Research Council of Norway through the NOTUR project EMEP (NN2890K) for CPU, and NorStore project European Monitoring and Evaluation Programme (NS9005K) for storage of data. The research presented is a contribution to the Swedish strategic research area ModElling the Regional and Global Earth system, MERGE. This work was supported by Formas (grant numbers 214-2010-1756, 942-2015-1537); the Swedish Research Council (grant number 2014-5332) and the European Research Council (Starting grant no 638703, "COALA"). ÅMH acknowledge Formas (214-2013-1430) and Vinnova, Sweden's Innovation Agency (2013-03058), including support for her research stay at FZJ. Participation of the Manchester group was facilitated by the UK Natural Environment Research Council (NERC) funded CCN-Vol project (NE/L007827/1) and underpinning National Centre for Atmospheric Science (NCAS) funding.

\section{Data availability statements}

All data used are shown as Figures or Tables in the manuscript or in the supplemental information. Raw data are available from the corresponding author on reasonable request. 
Figure 1: Reduced SOA mass and yield of $\alpha$-pinene by product scavenging and $O H$ scavenging by isoprene.

The top panel depicts symbolically the transition of the reaction system. a: Neutral seed particles: isoprene (red triangles) lowered $[\mathrm{OH}]$ (black diamonds) and the corresponding consumption of $\alpha$-pinene (blue squares), reducing the organic mass dramatically. The organic mass was normalized to sulfate mass (organics $/ \mathrm{SO}_{4}{ }^{2-}$, green circles). The newly discovered product scavenging (red) in the presence of isoprene is separated from $\mathrm{OH}$ scavenging (orange) by re-adjustment of $[\mathrm{OH}]$. Because of product scavenging only $60 \%$ of the organic mass is formed despite the same $\alpha$-pinene consumption. (The acidic case is depicted in Figure S3.) Vertical error bars for $\Delta \alpha-$ pinene and $\Delta$ isoprene are s.d. for averaging 14-15 samples, horizontal bars show the averaging intervals. For $\mathrm{OH}$ we estimate an overall error of $\pm 33 \%$.

b: The SOA yields in presence of neutral ammonium sulfate (blue) and acidic ammonium bisulfate (red) seed particles were calculated at times $\underline{B}, \underline{C}$, and, $\underline{D}$ as organic mass/a-pinene consumption (acidic seed particles, see suppl. section 3). Not only the SOA mass (indicated by the green spheres in the middle) but also its yield decreased strongly (bar plots). $\underline{B}$ shows the SOA yield for $\alpha$-pinene alone, while $\underline{\mathrm{C}}$ shows the summed effect of the new product scavenging and $\mathrm{OH}$ scavenging in the $\alpha$ pinene \& isoprene reaction system. For the neutral seeds $\underline{D}$ demonstrates the magnitude of the product scavenging effect on the SOA yield, as $[\mathrm{OH}]$ and $\alpha$-pinene consumption were re-adjusted to the same levels as before isoprene addition. On acidic seed aerosol (red) isoprene makes a substantial contribution to SOA, which compensates for some of the $\mathrm{OH}$ scavenging effect and most of the product scavenging effect. The errors reflect the estimated overall $15 \%$ uncertainty for an individual experiment.

Figure 2: The reduction of the SOA yield of $\alpha$-pinene by isoprene as a function of the isoprene/ $\alpha$-pinene consumption ( $\Delta$ isoprene/ $\Delta \alpha$-pinene).

The actual SOA yield of $\alpha$-pinene (yact $=\Delta$ organic mass $/ \Delta \alpha$-pinene) in $\alpha$-pinene $\&$ isoprene mixtures was normalized to the average SOA yield obtained with $\alpha$-pineneonly (уAP) at same conditions for neutral (blue) and acidic seeds (red). The grey area indicates the $\pm 20 \%$ band for the scattering of the $\alpha$-pinene-only yields around $\mathrm{y}_{\mathrm{AP}}=$ 0.17 which includes the $15 \%$ error in the individual SOA mass yields (vertical bars) and the variability of the experimental conditions for the reaction system with $\alpha$-pineneonly. Horizontal error bars show the uncertainties of the isoprene/ $\alpha$-pinene ratio $( \pm 10 \%)$ derived from the measurement errors of the compounds.

The dashed line is the fit to the results for the neutral seeds that was implemented in the global model calculations to parametrize product scavenging: $\mathrm{y}_{\text {act }}=y_{A P} \cdot(0.48+0.52 \cdot \exp [-1.53 \cdot(\Delta$ isoprene/ $\Delta \alpha-$ pinene $)])$ 
548 Figure 3: HOM monomer/dimer distribution in the presence and absence of isoprene illustrating the product scavenging effect. a: comparison of two mass spectra taken in experiments with (orange) and without isoprene (blue). In the presence of isoprene the dimer/monomer drops to about $1 / 3$, indicating that the formation of these extremely low vapour pressure compounds is efficiently suppressed in the presence of isoprene. b: Both the total HOM (monomers+dimers, circles) and HOM dimers (squares, molecular mass $>370 \mathrm{Da}$ ) decrease with decreasing $\alpha$-pinene turnover. Here $[\mathrm{OH}]$ was varied in two different ways: i) by decreasing the $\mathrm{OH}$ production rate, i.e. by decreasing the photolysis of ozone $\left(\mathrm{J}\left(\mathrm{O}^{1} \mathrm{D}\right)\right.$, blue) and ii) by adding increasing amounts of isoprene (red). In the presence of isoprene HOM decrease more strongly, mainly because the product scavenging is suppressing the $\alpha$-pinene HOM dimers. The total HOM from the two different experiments were normalized to 1 for better comparison. c: Estimate of the product scavenging effect on $\alpha$-pinene HOM dimers by isoprene at turnover $5.0 \times 10^{7}$ $\mathrm{cm}^{-3} \mathrm{~s}^{-1}$ based on molecular mass weighted signals in the mass spectra (details in Figure S8). Data for $\alpha$-pinene-only were interpolated from the nearest $\mathrm{J}\left(\mathrm{O}^{1} \mathrm{D}\right)$ data (arrows in b). The reduction in total HOM mass is $33 \%$, to which dimers (dark green) contribute $26 \%$ and monomers 7\% (light green). Error bars show the s.d. of the averages over 31 data points. The suppression of $\alpha$-pinene HOM dimers of $26 \%$ explains most of the $35 \%$ product scavenging derived from reduced SOA formation in Figure 1 . The balance is a result of the reduced yield of HOM monomers and/or shifts in their volatility spectrum.

Figure 4: Suppression of $\alpha$-pinene SOA in presence of CO illustrating the generality of the product scavenging effect.

a: comparison of three mass spectra taken in experiments with (orange $[\mathrm{CO}]=10 \mathrm{ppm}$, red $[\mathrm{CO}]=57 \mathrm{ppm}$ ) and without $\mathrm{CO}$ (blue). In the presence of $[\mathrm{CO}]>10 \mathrm{ppm}$ the dimer/monomer drops by more than $1 / 2$, indicating that the formation of the dimers is efficiently suppressed in the presence of $\mathrm{CO}$. Because of the high [CO] overall HOM are suppressed by factor of 4 and 5 respectively. b: The product scavenging effect reduces the $\alpha$-pinene yield in the reaction system $\alpha$-pinene \& CO \& OH in the presence of ammonium sulfate seeds. The actual SOA yield, calculated as actual organic mass/actual $\alpha$-pinene consumption, decreases by more than $50 \%$, when 40 ppm CO was added to the reaction system. $\mathrm{CO}$ concentrations were calculated from known inlet concentration, the flow rate through the $\mathrm{RC}$ and the reaction rate of $\mathrm{CO}$ with $\mathrm{OH}$. Light colored data points show steady state averages, whereby horizontal error bars show the averaging interval; s.d. of the averages are of the same size or smaller than the symbols. Note, panels a and $\mathbf{b}$ were not taken from the same experiment: experiments to show HOM in the gas-phase and to show SOA suppression cannot be performed in optimal fashion under the same conditions. To measure the unperturbed HOM-MS, particle formation must be avoided. In contrast, mass formation and its suppression must be determined in presence of seed surface as HOM losses at the walls of the chamber have to be minimized. Therefore, the experiment to measure the HOM-MS was performed without seed aerosol whereas ammonium sulfate particles were added to measure the suppression of mass formation by $\mathrm{CO}$. Otherwise the conditions of the experiments were similar. 
597 Figure 5: Atmospheric implications of product scavenging and $\mathrm{OH}$ scavenging.

598 Global model calculations showing that $\mathrm{OH}$ scavenging (OHS) and product scavenging (PS) in presence of isoprene reduce the photochemically derived MT-OH-SOA mass (red) significantly compared to the reference cases NoIso. For the calculation a $4 \%$ iSOA yield for acidic aerosols was applied (sum of the brownish bars). OHS is inherently considered in models as long as biogenic SOA (BSOA) formation is directly linked to the oxidant fields, but the new PS effect reduces the MT-OH-SOA even further. To illustrate the maximum potential PS effect it was also applied to ozone derived $\mathrm{MT}_{-} \mathrm{O}_{3}-\mathrm{SOA}$ (orange, PSOx). In this case the iSOA gain for $1 \%$ iSOA yield on neutral aerosols (dark brown) would not be able to compensate for the loss of MT-SOA. We show the global average and results for regions with high and low isoprene emissions and high and low population density. The map shows isoprene emissions, green shaded in $\left[\mathrm{mg} \mathrm{m}^{-2}\right]$ and the areas of the selected regions. All contributions are normalised to MT-OH-SOA of the respective NoIso case, when biogenic isoprene emissions were omitted in the model (suppl. section 8). 

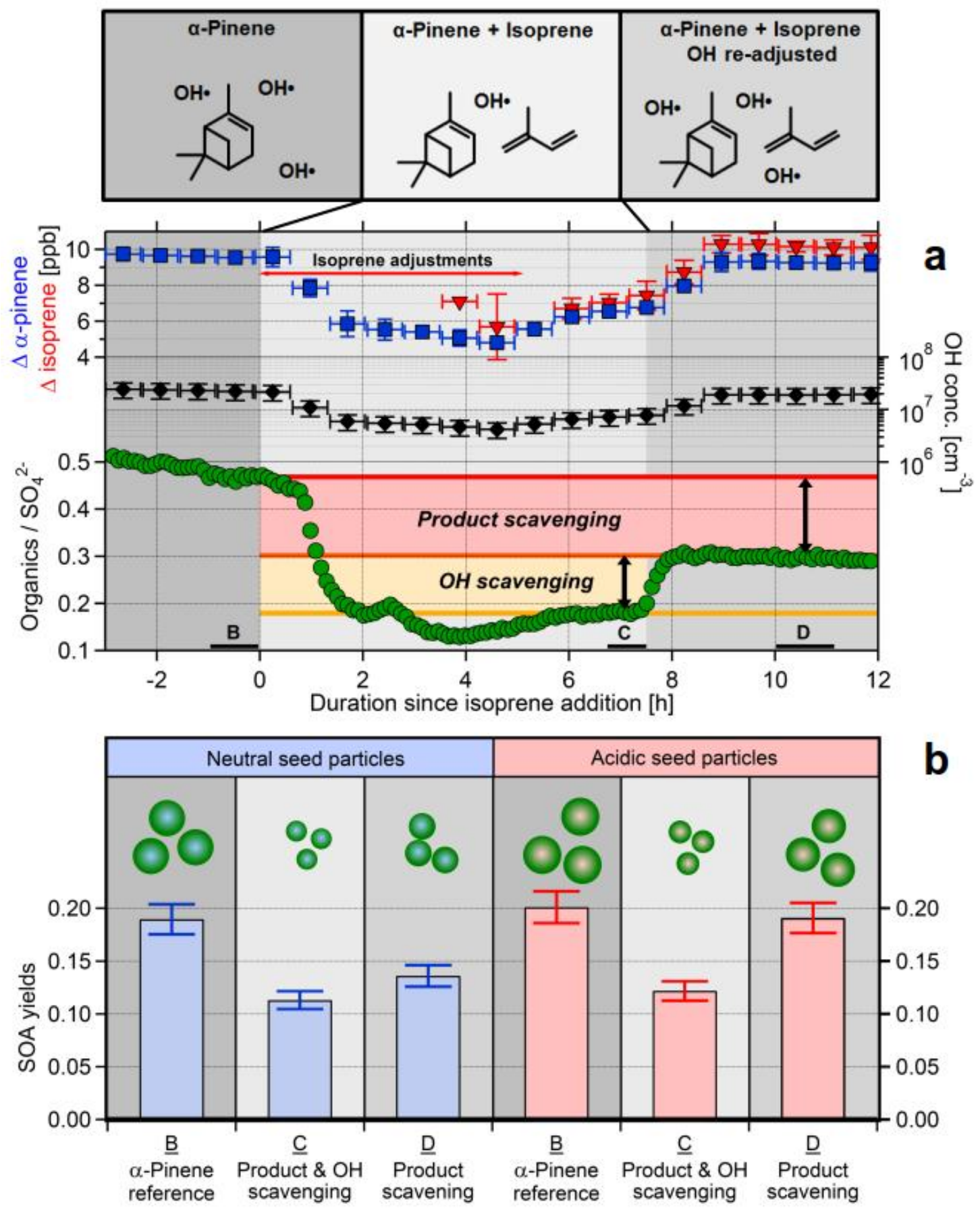

613

614

615

Figure 1.

616 


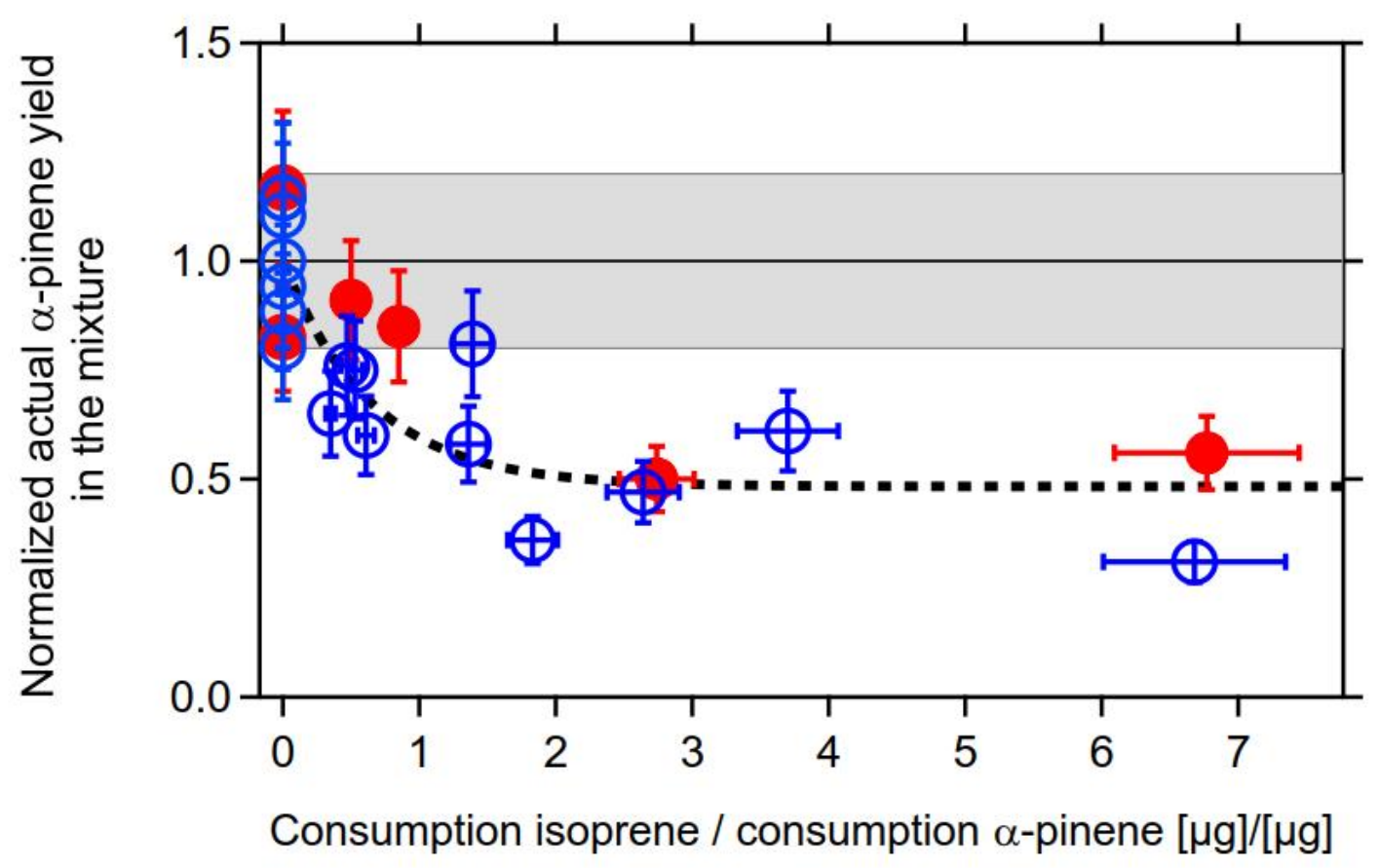

617

618

619

620

Figure 2. 

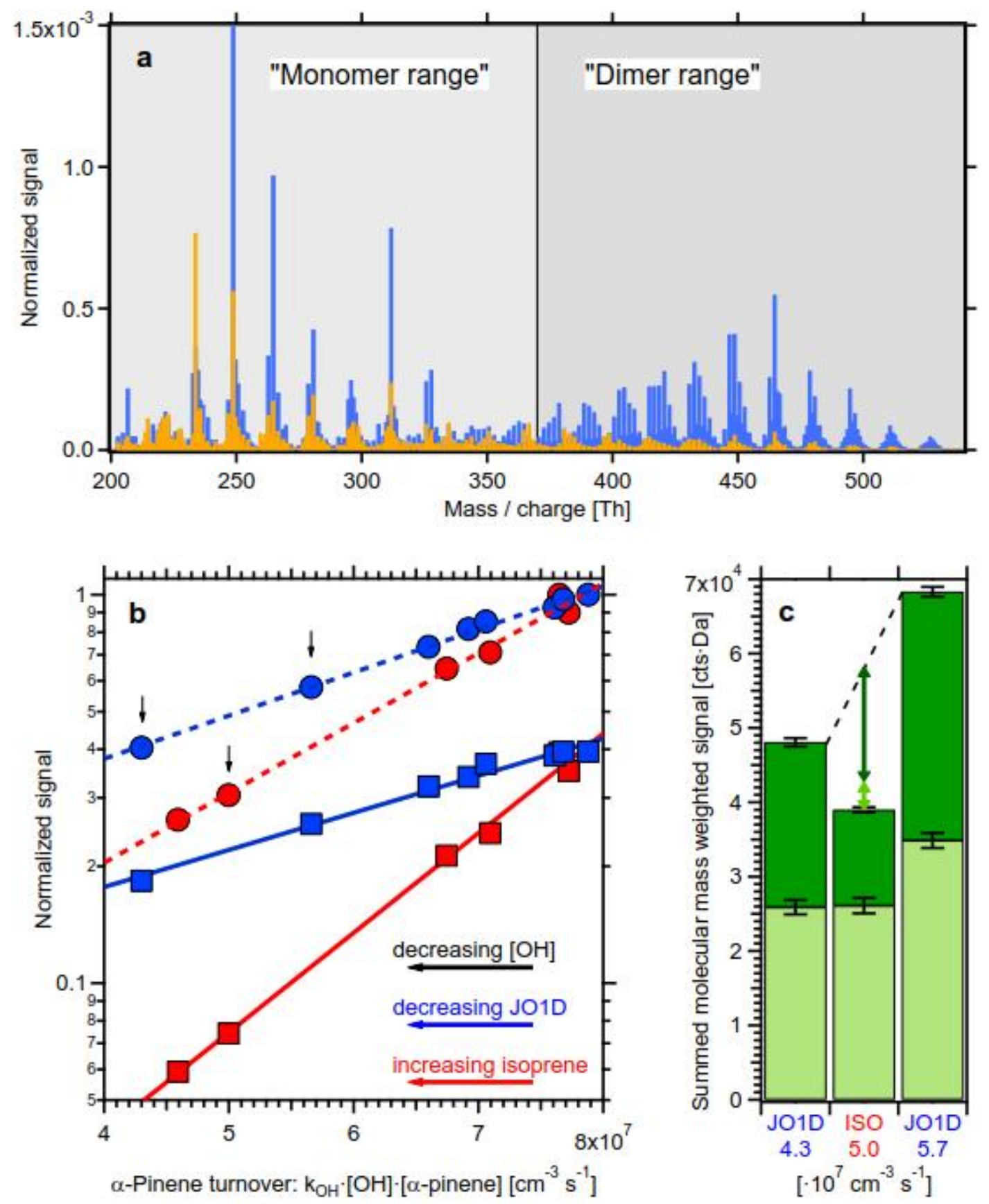

621
622

Figure 3.

623

624 


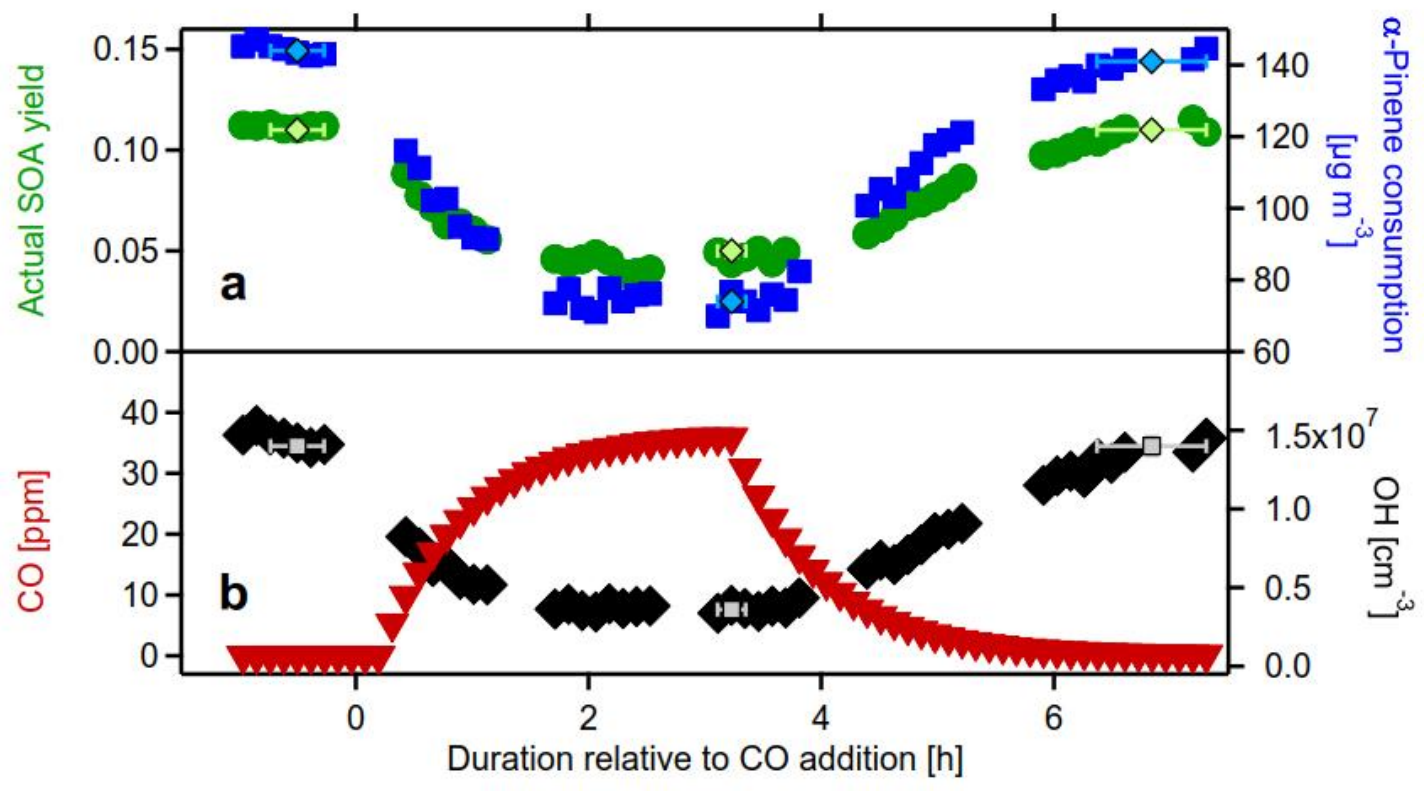

625

626

Figure 4.

627

628
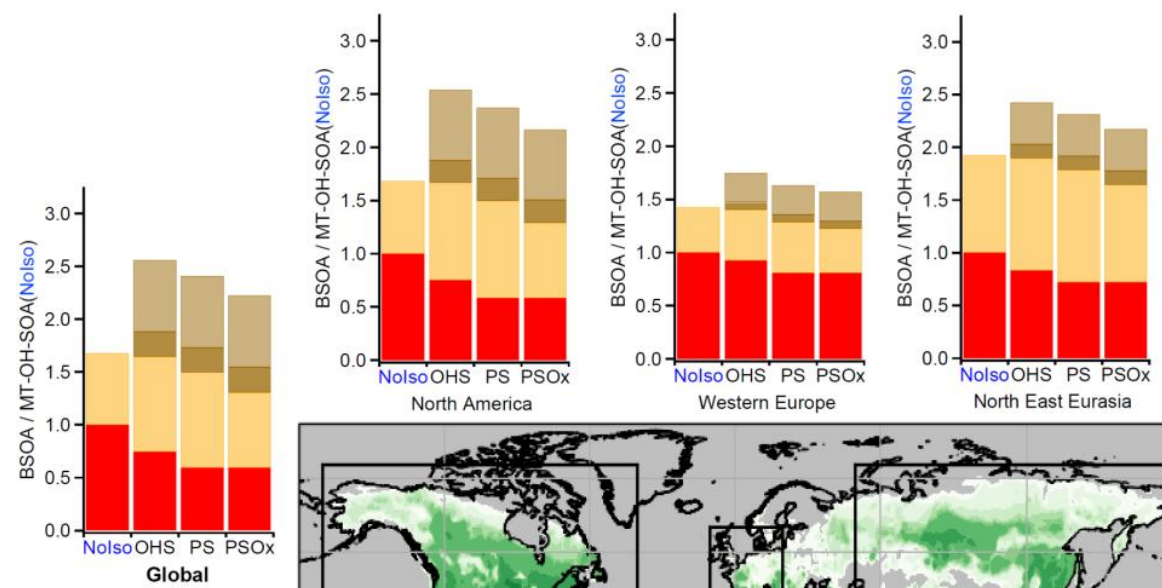

iSOA (yield $=4 \%$ )

- iSOA (yield $=1 \%$

- $\mathrm{MT}_{-} \mathrm{O}_{3}-\mathrm{SOA}$

- MT-OH-SOA
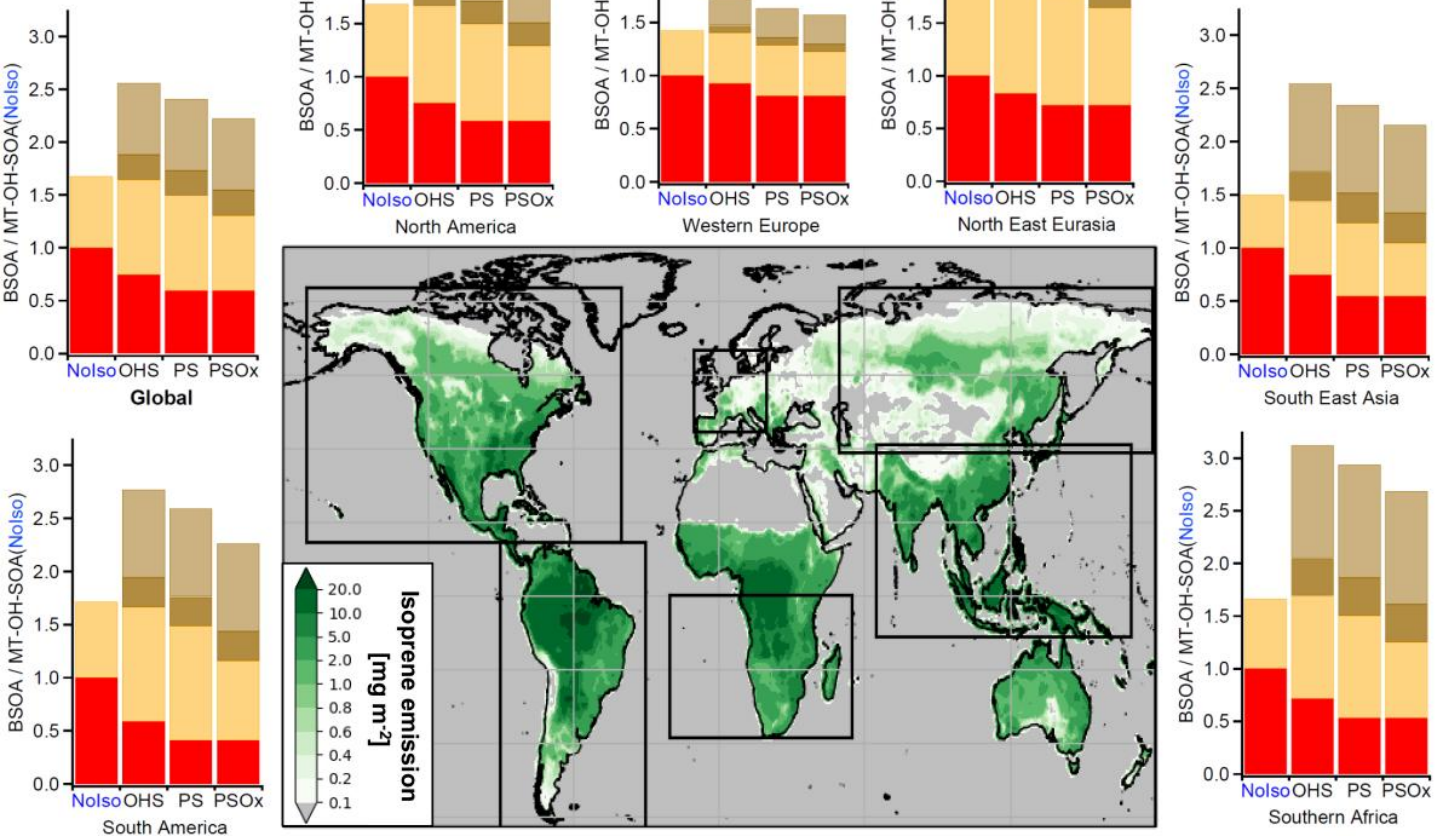

630 Figure 5.

631 